International Journal of Engineering \& Technology, $7(2.23)(2018) 328-331$
International Journal of Engineering \& Technology
Website: $w w w . s c i e n c e p u b c o . c o m / i n d e x . p h p / I J E T$
Research paper

\title{
Plastic tension of porous plates due pure bending
}

\author{
Levonyan H. $\mathrm{L}^{1 *}$, Verlinski S. ${ }^{1}$, Tyagunov A. G ${ }^{2}$, Tarasov D. $A^{.2}$ \\ ${ }^{I}$ National Engineering University of Armenia, Chair of Mechanics and Machine Science \\ ${ }^{2}$ Ural Federal University, Institute of Radio electronics and Technologies \\ *Corresponding author E-mail: hayk_levonyan@mail.ru
}

\begin{abstract}
The bending of the plate from rigid-plastic hardening material in the condition of plane deformation is investigated by analytical and numerical methods. Based on equations of the theory of plasticity of the porous materials the solution of the problem is lead to integration of the nonlinear differential equation regard to radial stress. The position of neutral axis is defined by numerical integration and the stress strain state components are received. Graphics of stress components and porosity changing are constructed on the height of the plate. The same problem simulated in ABAQUS software with the help finite element method. The results are compared.
\end{abstract}

Keywords: Bending; Plate; Stress; Porosity; Numerical Integration; FEM; ABAQUS

\section{Introduction}

The R. Hill was first, who discussed theory of plate bending for rigid-plastic materials in big deformation, when the lateral stresses caused by the curvature are influence. The position of neutral axe after bending is received [1-3]. Same problem with hardening is investigated in [4-6].The problem about bending plate in big deformation is discussed. Assumed, that material is isotropic, pores are spherical, and common (non-porous) material is behavior according to theory of plasticity of porous materials [7]. The stress components of the rigid-plastic material in general criteria of plasticity of Huber-Misses for porous material are defined. The numerical example is solved, the results are shown.

The manufactures from porous materials have wide application in different fields of industry, as load-bearing parts also. Theoretical and experimental works for plastic deformation of porous materials and solving practical problems of pressure treatment of powder materials are reviewed in [8]. During loading, the mechanical properties of porous material are changing. Researching of properties in deformation give good opportunity maximum use safety factors.

\section{Problem description. basic equations}

The aim of the paper is to propose a numerical method for determining the stress-strain state of a sintered body in the presence of porosity. The concept of a neutral axis is used, with respect to which the porosity of the material changes during bending: when bending, the porosity of the lower part of the plate decreases, the upper part increases. The plastic tension of the plate from homogeneous sintered porous material due pure bending is discussed. The plate is bending by the arc of a circle because of the external activity (Fig.1). In big deformation, when radius of curvature not less than 5 thickness of the plate because of big deformations, the $\sigma_{\mathrm{r}}$ and $\sigma_{\mathrm{z}}$ components are appear, and elastic deformations as compared with the plastic, may be neglected.
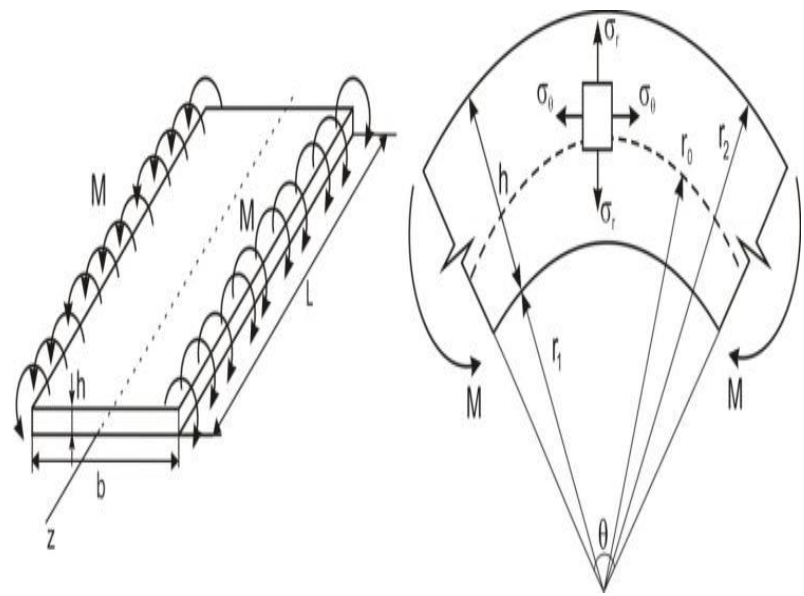

Fig. 1: Plate under Bending.

Basic equations are given in cylindrical coordinates system. The equilibrium differential equations have the following form:

$$
\left\{\begin{array}{l}
\frac{\partial \sigma_{\mathrm{r}}}{\partial \mathrm{r}}+\frac{1}{\mathrm{r}} \frac{\partial \tau_{\mathrm{r} \theta}}{\partial \theta}+\frac{\partial \sigma_{\mathrm{rz}}}{\partial \mathrm{z}}+\frac{\sigma_{\mathrm{r}}-\sigma_{\theta}}{\mathrm{r}}=0 \\
\frac{\partial \tau_{\mathrm{r} \theta}}{\partial \mathrm{r}}+\frac{1}{\mathrm{r}} \frac{\partial \sigma_{\theta}}{\partial \theta}+\frac{\partial \tau_{\theta \mathrm{z}}}{\partial \mathrm{z}}+\frac{2 \tau_{\mathrm{r} \theta}}{\mathrm{r}}=0 \\
\frac{\partial \tau_{\mathrm{r} \theta}}{\partial \mathrm{r}}+\frac{1}{\mathrm{r}} \frac{\partial \tau_{\theta \mathrm{z}}}{\partial \theta}+\frac{\partial \sigma_{\mathrm{z}}}{\partial \mathrm{z}}+\frac{\tau_{\mathrm{rz}}}{\mathrm{r}}=0
\end{array}\right.
$$

Generalized Huber-Mises'splasticity conditions for porous materials expressed through main stresses [1-9]:

$$
\begin{aligned}
& \left(\sigma_{1}-\sigma_{2}\right)^{2}+\left(\sigma_{2}-\sigma_{3}\right)^{2}+\left(\sigma_{1}-\sigma_{3}\right)^{2}+ \\
& +2 \alpha^{\mathrm{m}}\left(\sigma_{1}+\sigma_{2}+\sigma_{3}\right)^{2}=2 \beta^{2 \mathrm{n}+1} \sigma_{\mathrm{Y}}^{2}
\end{aligned}
$$

By the theory of flow of porous isotropic materials, stress-deformation relationship will be follow: 


$$
\left\{\begin{array}{l}
\mathrm{d} \varepsilon_{1}=\frac{3}{2} \frac{\mathrm{d} \lambda}{\beta^{3 n}}\left(\sigma_{1}-\left(1-2 \alpha^{\mathrm{m}}\right) \sigma_{0}\right) \\
\mathrm{d} \varepsilon_{2}=\frac{3}{2} \frac{\mathrm{d} \lambda}{\beta^{3 \mathrm{n}}}\left(\sigma_{2}-\left(1-2 \alpha^{\mathrm{m}}\right) \sigma_{0}\right) \\
\mathrm{d} \varepsilon_{3}=\frac{3}{2} \frac{\mathrm{d} \lambda}{\beta^{3 \mathrm{n}}}\left(\sigma_{3}-\left(1-2 \alpha^{\mathrm{m}}\right) \sigma_{0}\right) .
\end{array}\right.
$$

where $\mathrm{d} \lambda=\frac{\mathrm{d} \varepsilon_{\mathrm{eq}}}{\sigma_{\mathrm{eq}}}$,

$\mathrm{d} \varepsilon_{\mathrm{eq}}=\frac{\beta^{2 \mathrm{n}-0,5}}{3} \times$

$\sqrt{2\left[\left(\mathrm{~d} \varepsilon_{1}-\mathrm{d} \varepsilon_{2}\right)^{2}+\left(\mathrm{d} \varepsilon_{2}-\mathrm{d} \varepsilon_{3}\right)^{2}+\left(\mathrm{d} \varepsilon_{3}-\mathrm{d} \varepsilon_{1}\right)^{2}\right]}$,

$\sigma_{\mathrm{eq}}=\frac{1}{\sqrt{2} \beta^{\mathrm{n}+0,5}} \times$

$\sqrt{\left(\sigma_{1}-\sigma_{2}\right)^{2}+\left(\sigma_{2}-\sigma_{3}\right)^{2}+\left(\sigma_{3}-\sigma_{1}\right)^{2}+2 \alpha^{\mathrm{m}}\left(\sigma_{1}+\sigma_{2}+\sigma_{3}\right)^{2}}$,

$\sigma_{0}-$ Average normal stress: $\sigma_{0}=\frac{1}{3}\left(\sigma_{1}+\sigma_{2}+\sigma_{3}\right)$,

$\mathrm{d} \varepsilon_{0}-$ Average deformation differences:

$\mathrm{d} \varepsilon_{0}=\frac{1}{3}\left(\mathrm{~d} \varepsilon_{1}+\mathrm{d} \varepsilon_{2}+\mathrm{d} \varepsilon_{3}\right)$

$\alpha, \beta$ - functions of porous materials, $\mathrm{m}$ - porous parameter, $\mathrm{n}$ - parameter, which reduce mechanical properties of porous material to properties of non-porous.m and $\mathrm{n}$ parameters are defined by experiment data on uniaxial compression of cylindrical examples from porous material

From the relations ( 3 ) the condition of mass conservation we obtain:

$\mathrm{d} \varepsilon_{1}+\mathrm{d} \varepsilon_{2}+\mathrm{d} \varepsilon_{3}=\frac{9 \mathrm{~d} \lambda \alpha^{\mathrm{m}} \sigma_{0}}{\beta^{3 \mathrm{n}}}$

Or

$\frac{\mathrm{dv}}{1-\mathrm{v}}=\frac{9 \alpha^{\mathrm{m}} \mathrm{d} \lambda \sigma_{0}}{\beta^{3 \mathrm{n}}}$,

wherevis current porosity of material.

Assumed, that for discussed porous material the experimental diagram $\sigma_{\text {eq }}-\int \mathrm{d} \varepsilon_{\text {eq }}$ is known and approximated any $\sigma_{\text {eq }}=\mathrm{f}\left(\varepsilon_{\text {eq }}\right)$ function.

Tangential stresses $\left(\tau_{\mathrm{r} \theta}, \tau_{\mathrm{rz}}, \tau_{\theta \mathrm{z}}\right)$ are absent in pure bending, hence, $\sigma_{\mathrm{r}}, \sigma_{\theta}$ and $\sigma_{\mathrm{z}}$ stress components are main, i.e. $\sigma_{1}=\sigma_{\mathrm{r}}, \sigma_{2}=$ $\sigma_{\theta}, \sigma_{3}=\sigma_{\mathrm{z}}$. As stresses and deformations are not depend on $\theta$ polar angle, so from equilibrium differential equations (1) will be received follow expression:

$\frac{\mathrm{d} \sigma_{\mathrm{r}}}{\mathrm{dr}}+\frac{\sigma_{\mathrm{r}}-\sigma_{\theta}}{\mathrm{r}}=0$

So, the plate is deformed in plane strain conditions, i.e.d $\varepsilon_{\mathrm{z}}=0$.

From stress-deformation relation (3) we have:

$\sigma_{\mathrm{z}}=\frac{1-2 \alpha^{\mathrm{m}}}{2\left(1+\alpha^{\mathrm{m}}\right)}\left(\sigma_{\mathrm{r}}+\sigma_{\theta}\right)$

From (4) is following, that

$d \varepsilon_{\text {eq }}=\frac{\beta^{2 \mathrm{n}-0,5}}{3 \alpha^{0,5 \mathrm{~m}}} \sqrt{\left(1+4 \alpha^{\mathrm{m}}\right)\left(\mathrm{d} \varepsilon_{\mathrm{r}}^{2}+\mathrm{d} \varepsilon_{\theta}^{2}\right)+2\left(1+4 \alpha^{\mathrm{m}}\right) \mathrm{d} \varepsilon_{\mathrm{r}} \mathrm{d} \varepsilon_{\theta}}$. (9)

Substituting (8) into the (5), will be received follow formula:

$\sigma_{\text {eq }}=\frac{\sqrt{3}}{2\left(1+\alpha^{\mathrm{m}}\right) \beta^{\mathrm{n}+0,5}} \times$
$\frac{\times \sqrt{\left(1+5 \alpha^{\mathrm{m}}+4 \alpha^{2 \mathrm{~m}}\right)\left(\sigma_{\mathrm{r}}^{2}+\sigma_{\theta}^{2}\right)-}}{-2\left(1-\alpha^{\mathrm{m}}-2 \alpha^{2 \mathrm{~m}}\right) \sigma_{\mathrm{r}} \sigma_{\theta}}$
From (6) follow, that

$\frac{\mathrm{dv}}{1-\mathrm{v}}=\frac{9 \alpha^{\mathrm{m}} \mathrm{d} \lambda\left(\sigma_{\mathrm{r}} \sigma_{\theta}\right)}{2\left(1+\alpha^{\mathrm{m}}\right) \beta^{3 \mathrm{n}}}$

If material isrigid-plastic, then the problem is static defined and from (2), (7) and (8) equation systems the components of stresses $\sigma_{\mathrm{r}}, \sigma_{\theta}$ and $\sigma_{\mathrm{z}}$ are determined.

Substituting (8) into the (2), after transformations will be received follow formula:

$$
\begin{aligned}
& \left(1+5 \alpha^{\mathrm{m}}+4 \alpha^{2 \mathrm{~m}}\right) \sigma_{\theta}^{2}-2\left(1-\alpha^{\mathrm{m}}-2 \alpha^{2 \mathrm{~m}}\right) \sigma_{\mathrm{r}} \sigma_{\theta}+\left(1+5 \alpha^{\mathrm{m}}+\right. \\
& \left.+4 \alpha^{2 \mathrm{~m}}\right) \sigma_{\mathrm{r}}^{2}-\frac{4}{3}\left(1+\alpha^{\mathrm{m}}\right)^{2} \beta^{2 \mathrm{n}+1} \mathrm{Y}^{2}=0
\end{aligned}
$$

Solving (12) regard $\sigma_{\theta}$, will be received:

In $r \in\left[\mathrm{r}_{1}, \mathrm{r}_{0}\right]$ - stretched zone

$\sigma_{\theta}=\frac{\left(1-\alpha^{\mathrm{m}}-2 \alpha^{2 \mathrm{~m}}\right) \sigma_{\mathrm{r}}-\sqrt{\mathrm{A}(\alpha) \beta^{2 \mathrm{n}+1} \mathrm{Y}^{2}-\mathrm{B}(\alpha) \sigma_{\mathrm{r}}^{2}}}{1+5 \alpha^{\mathrm{m}}+4 \alpha^{2 \mathrm{~m}}}$

In $\in\left[\mathrm{r}_{0}, \mathrm{r}_{2}\right]$ - compressed zone;

$\sigma_{\theta}=\frac{\left(1-\alpha^{m}-2 \alpha^{2 m}\right) \sigma_{r}+\sqrt{A(\alpha) \beta^{2 n+1} Y^{2}-B(\alpha) \sigma_{r}^{2}}}{1+5 \alpha^{m}+4 \alpha^{2 m}}$

Wherer0- radius of neutral layer.

Substituting expression of $\boldsymbol{\sigma}_{\boldsymbol{\theta}}$ to (7), we will received non-linear differential equation concerning $\sigma_{r}$ :

$\frac{d \sigma_{r}}{d r}-\frac{2 \alpha^{m}\left(3+2 \alpha^{m}\right) \sigma_{r} \pm \sqrt{A(\alpha) \beta^{2 n+1} Y^{2}-B(\alpha) \sigma_{r}^{2}}}{\left(1+5 \alpha^{m}+4 \alpha^{2 m}\right) r}=0$

Where

$\mathrm{A}(\alpha)=\frac{4}{3}\left(1+7 \alpha^{m}+7 \alpha^{2 m}+13 \alpha^{3 m}+4 \alpha^{4 m}\right)$

$B(\alpha)=12 \alpha^{m}\left(1+\alpha^{m}\right)^{3}$

Boundary conditions of the problem (Fig. 1) are follow:

$\mathrm{In}=\mathrm{r}_{1}, \sigma_{\mathrm{r}}=0$,

In $\mathrm{r}=\mathrm{r}_{2}, \sigma_{\mathrm{r}}=0$,

In neutral layer $\left(\mathrm{r}=\mathrm{r}_{0}\right)$ we have $\sigma_{\mathrm{r} 1}=\sigma_{\mathrm{r} 2}$.

$\sigma_{\mathrm{r} 1}=\sigma_{\mathrm{r} 2}$ condition is determinate position of neutral surface $\mathrm{inr}=\mathrm{r}_{0}$. The magnitude of the bending momentum per unit of width of the plate represented by $\boldsymbol{\sigma}_{\boldsymbol{\theta}}$ :

$M=\int_{r_{1}}^{r_{2}} \sigma_{\theta}\left(r-r_{0}\right) d r$

Therefore, our problem reduces to integrate as non-linear differential equations (15) with boundary condition (18).

Note, that in big deformations current material $v$ porosity stay unknown function from $r$, and complicates solution of the problem. It is might integrated equation (15) only applying numerical successive approximations method.

In particular case, for ideal rigid-plastic non-porous material ( $\alpha=$ $0, \beta=1$ ), equation (15) integrated and received known solutions [3].

\section{Numerical example and results}

Let discuss problem described above on the numerical method. Let we have steel porous plate with the follow parameters: initial porosity $v_{0}=0.1$. It contains additional $\mathrm{Ni} 4 \%, \mathrm{Cu} 1.5 \%$, Mo $0.5 \%$, 
sintered in 20 min in the $\mathrm{N}_{2} 95 \%$ and $\mathrm{H}_{2} 5 \%$ environment. Functions of porosity are $\alpha=v, \beta=1-v$. So, porosity parametersm $=1.1 n=1.4$, and $\sigma_{Y}=630 \mathrm{MPa}$ [9].

Plate divided on to many strips. By [4], two nearest each other strips with unit width step by step is investigated. Taking, that during the transition from the first to the second strain state increment of radial deformation $\boldsymbol{d} \boldsymbol{\varepsilon}_{\boldsymbol{r}}$ and circumferential deformation $\boldsymbol{d} \boldsymbol{\varepsilon}_{\boldsymbol{\theta}}$ can be considered small, and increment of circumferential deformation in transverse cross-section changes by the linear law (the hypothesis of plane sections):

$d \varepsilon_{\theta}=y / r$

wherey is the distance from neutral layer to current discussed layer. For this example the method of numerical integration, applied in [7], is used with one difference.Here integration starts from neutral layer, where porosity is equal to initial $\boldsymbol{v}_{0}$. In other layers the porosity is change because of deformation and is not known in advance. In the stretched and compressed zones numerical integration does separate by y starting from neutral layer. The calculation continuous by the successive approximations method till boundary conditions (18) will be satisfied.

Table 1: Components of the Stress-Deformation Tension in $\boldsymbol{v}_{0}=0.1$

\begin{tabular}{cllll}
\hline$r, m$ & \multicolumn{1}{c}{$\sigma_{r}, M P a$} & \multicolumn{1}{c}{$\sigma_{\theta}, M P a$} & \multicolumn{1}{c}{$\sigma_{z}, M P a$} & $\rho=1-v$ \\
\hline 0.3494 & 0.3569 & 525.7766 & 203.2506 & 0.1029 \\
0.3474 & -2.646 & 523.8829 & 201.3627 & 0.1029 \\
0.3454 & -5.6599 & 521.9841 & 199.4728 & 0.1029 \\
0.3434 & -8.685 & 520.0947 & 197.5911 & 0.1029 \\
0.3414 & -11.7214 & 518.2467 & 195.7408 & 0.1028 \\
0.3394 & -14.7695 & 516.5124 & 193.9734 & 0.1027 \\
0.3374 & -17.8303 & 515.0549 & 192.4054 & 0.1024 \\
0.3354 & -20.9056 & 514.248 & 191.3033 & 0.1016 \\
0.3334 & -24 & 515.046 & 191.3207 & 0.1 \\
0.3334 & -24 & -545.6854 & -221.9601 & 0.1 \\
0.3314 & -20.7286 & -547.0716 & -222.4447 & 0.0981 \\
0.3294 & -17.4342 & -546.705 & -221.596 & 0.0972 \\
0.3274 & -14.1215 & -545.4285 & -220.0714 & 0.0967 \\
0.3254 & -10.793 & -543.7036 & -218.2144 & 0.0965 \\
0.3234 & -7.4495 & -541.7544 & -216.1923 & 0.0964 \\
0.3214 & -4.0917 & -539.6885 & -214.0852 & 0.0964 \\
0.3194 & -0.7197 & -537.5569 & -211.9311 & 0.0964 \\
\hline
\end{tabular}

On Fig. 2 and Fig.3 are constracted epuras for $\sigma_{r}, \sigma_{\theta}$ and $\sigma_{z}$ stresses, and it is clear see the changing position of neutral layer $\left(\mathrm{r}_{0}=0.3334\right)$.

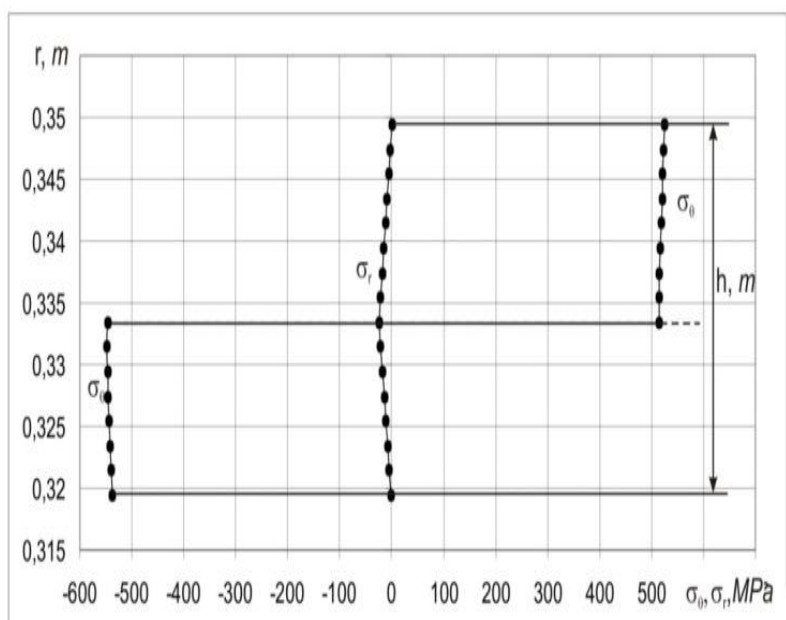

Fig. 2: Graphics of $\sigma_{r}$ and $\sigma_{\theta}$ Stresses Depending Onh Height of the Plate.

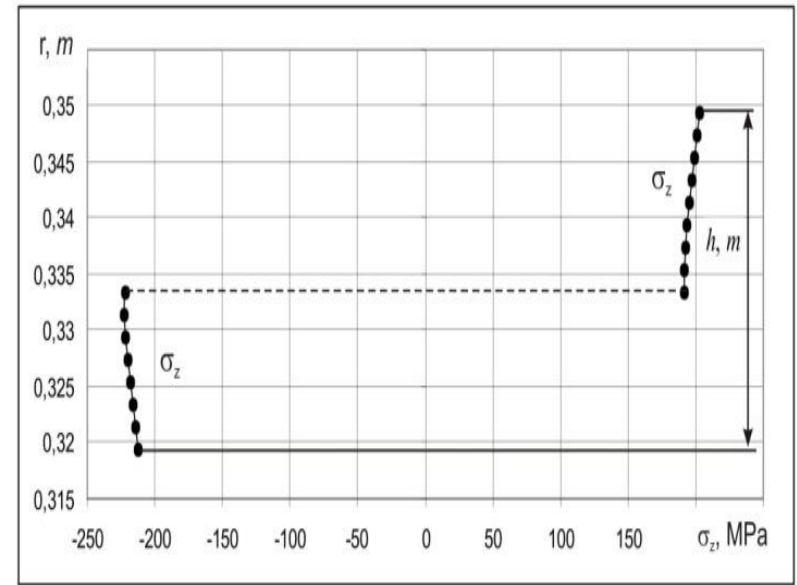

Fig. 3: Graphic of $\sigma_{z}$ Stress Depending on h Height of the Plate.

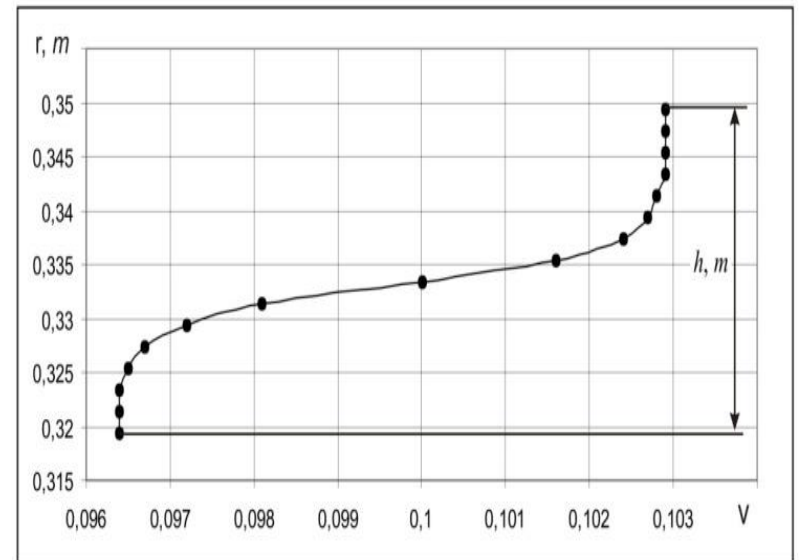

Fig. 4: Graphic for Variation of Porosity $\boldsymbol{v}$ depend on h Height of the Plate.

On Fig. 4 is presented variation of porosity $\boldsymbol{v}$ depending on h height of the plate.

\section{FEM simulation}

With the help ABAQUS finite element method software the stresses of the plate in case, when porosity of the plane is equal 0.1 , is simulated and calculated.

Table 2: Properties of the Material

\begin{tabular}{llllll}
\hline $\begin{array}{l}\text { Density, } \\
\mathrm{kg}^{*} \mathrm{~m}^{-3}\end{array}$ & $\begin{array}{l}\text { Young } \\
\text { modulus, } \\
\mathrm{Pa}\end{array}$ & $\begin{array}{l}\text { Poison } \\
\text { ratio }\end{array}$ & $\begin{array}{l}\text { Yeld } \\
\text { stress }\end{array}$ & $\begin{array}{l}\text { Plastic } \\
\text { strain }\end{array}$ & Porosity \\
\hline 7872 & $210 \cdot 10^{6}$ & 0.29 & $\begin{array}{l}200 \cdot 10^{6} \\
\div 480 \cdot 10^{6}\end{array}$ & $\begin{array}{l}0 \div \\
0.18\end{array}$ & 0.1 \\
\hline
\end{tabular}

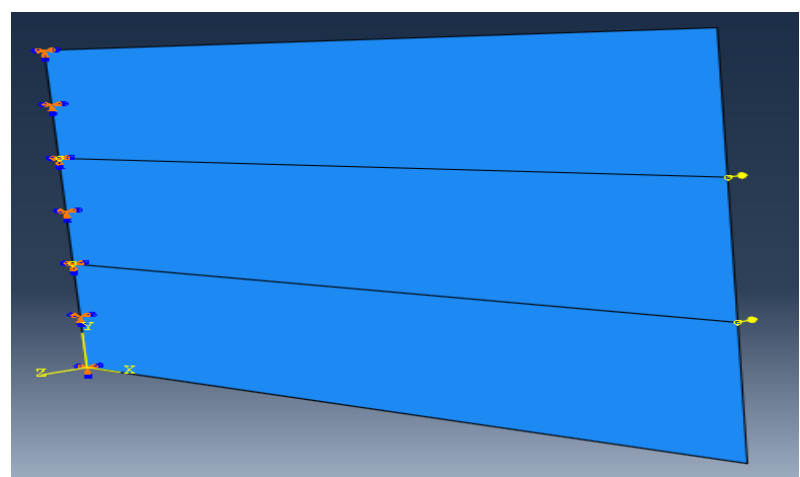

Fig. 5: Simulated in ABAQUS Model with the Boundary Conditions.

Initially, the plate with the sizes $30.0 \mathrm{sm} \times 50.0 \mathrm{sm}$ and $3 \mathrm{sm}$ was created. Follow properties are used (Table 2). 
Then, one side of the plane is fixed, the bending moment from the oposite side is applied. As result follow von Misses stresses are received (Fig. 6):

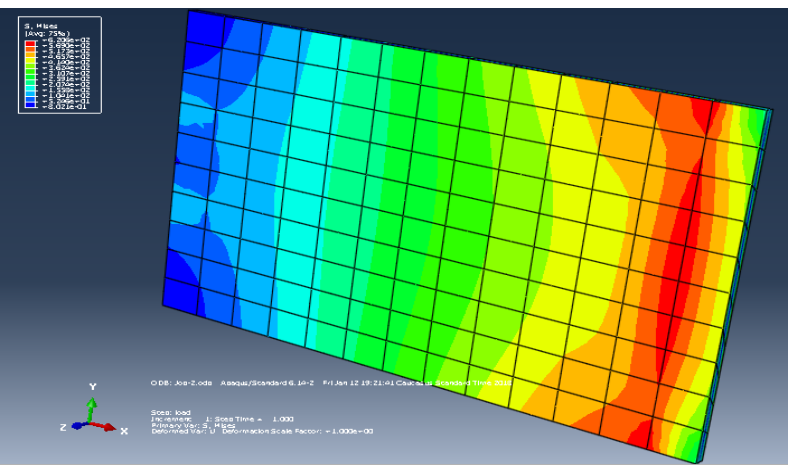

Fig. 6: Von Misses Stresses of the Porous Plane.

For analytical results compare with the simulation results we do follow. From the Table 1 first line results are input to the equation (5).

As Results, for Neutral Layer in (From Table 1)

\begin{tabular}{cllll}
\hline $\mathrm{r}, \mathrm{m}$ & $\sigma_{\mathrm{r}}, \mathrm{MPa}$ & \multicolumn{1}{c}{$\sigma_{\theta}, \mathrm{MPa}$} & \multicolumn{1}{c}{$\sigma_{\mathrm{z}}, \mathrm{MPa}$} & $\rho=1-\mathrm{v}$ \\
\hline 0.3334 & -24 & 515.046 & 191.3207 & 0.1 \\
0.3334 & -24 & -545.6854 & -221.9601 & 0.1 \\
\hline
\end{tabular}

we have $\sigma=620.332 \mathrm{MPa}$.

As shown on Fig. 6, we have $\sigma=620.602 \mathrm{MPa}$.

\section{Discussion}

The problem of bending plate with porosity is solved.In numerical method for non-porous (usual) materials integration is started from lower surface, while for porous materials integration is started from neutral layer with integration step $\Delta \mathrm{r}=2 \mathrm{~mm}$. In case of porosity $\mathbf{v}_{0=} 0.1$ choosing increasing of deformation $\Delta \varepsilon_{\mathrm{eq}_{0}}=0.005$, all components of stress-deformation tension are received with the help of successive approximations method: the neutral layer radius $\left(\mathrm{r}_{0}=0.3334 \mathrm{~m}\right)$, internal radius $\left(\mathrm{r}_{1}=0.3194 \mathrm{~m}\right)$, outer radius $\left(\mathrm{r}_{2}=0.3494 \mathrm{~m}\right)$.

From the received results are follow, that

1) The graphics of radial and circumferential stresses have same form as in non-porous (usual) materials. $\sigma_{\theta}$ Is maximum in upper and lower surfaces of the plate, $\sigma_{\mathrm{r}}$ is maximum on neutral layer $\left(\max \left|\sigma_{\mathrm{r}}\right|=24 \mathrm{MPa}\right)$.

2) The relative density $(\rho=1-v)$ in compressed and stretched zones accordingly are 0.0964 and 0.1029 .

3) Bending problem for porous sintered material simulated in ABAQUS software and for neutral layer received the same results as analytical.

\section{References}

[1] Hill R. The mathematical theory of plasticity. Oxford 1950.

[2] Hill R., British Iron and Steel Research Association, Report $\mathrm{MW} / \mathrm{B} / 6 / 49$

[3] Petrosyan G.L., Petrosyan H.G., Levonyan H.L. On simplified formulas of the theory of plasticity of porous materials. // Conference of SEUA. - Yerevan, 2005. - V.2. - P. 411-413.

[4] Levonyan H.L., PetrosyanKh.L. Theoretical and practical features in the bending of a plate // Conference of SEUA. - Yerevan, 2006. V.1. - P. 226-229.

[5] Malinin N.N., Shirshov A.A. Plastic bending of the plate in big deformations. // Izvestia VUZ. Machine-building, 1965, №8.-pp. 187192.

[6] Beiss P., Petrosyan G.L., Levonyan H.L., Petrosyan H.G. Porous cylindrical sample of high plastic deformation for testing and mechan- ical property definition, Proceedings of engineering academy of Armenia scientific and technological collected articles, Volume 4, number 2, Yerevan 2007, p 212-216.

[7] Shirshov A.A. Investigation of plastic bending of the plate with hardening influence. // Izvestia VUZ. Machine-building, 1965, №7.- C. $168-174$

[8] Green R.J., A plasticity theory for porous solids, International Journal of Mechanical Sciences, 14, №4, 215-214(1972).

[9] Petrosyan G.L., Beiss P., Hambardzumyan A., Badalyan G. // Proceeding of AnnualSci. Conference of SEUA, - 2001.-V.1-pp.209211. 